\title{
Evolution of COVID-19 patients treated with ImmunoFormulation, a combination of nutraceuticals to reduce symptomatology and improve prognosis: a multi-centred, retrospective cohort study
}

Mariana Hernández ( $\nabla$ dradiazmariana@gmail.com )

Clinica Arvila Magna

Jully Urrea

Clinica Arvila Magna

Luciano Bascoy

Clinic Bascoy

Research Article

Keywords: COVID-19, SARS-CoV-2, transfer factor, clinical study

Posted Date: January 13th, 2021

DOI: https://doi.org/10.21203/rs.3.rs-133532/v2

License: (1) (i) This work is licensed under a Creative Commons Attribution 4.0 International License.

Read Full License 


\section{Abstract}

Background Although a vast knowledge has already been gathered on the pathophysiology of COVID-19, there are still limited, non-optimal treatment options. In this context, agents that can act on prophylaxis or as adjuvants to the therapies are of high value.

Methods In this paper, we describe a multicentre, retrospective, observational study to describe the course of SARS-CoV-2 disease in patients treated with ImmunoFormulation (IF), an add-on therapy developed to decrease duration of clinical symptoms. In parallel, a group of patients that did not receive IF was used for comparison (using standard of care treatment). A total of 39 patients were evaluated for their recovery rate, general symptoms and their severity, and adverse reactions.

Results Throughout the observational period, $90 \%$ of patients recovered in the IF cohort and $47.4 \%$ in the Control cohort $(p=0.0057)$. From the symptoms with statistically significant differences, the duration of symptoms (i.e., the time to recover from it) was shorter in the IF cohort than in control cohort (in days, average), especially for fever ( $2.25 \times 21.78)$, dry cough $(4.38 \times 24.00)$, dyspnoea $(3.67 \times 20.00)$, headache $(2.00 \times 26.50)$, diarrhoea $(5.25 \times 25.25)$, and weakness $(1.92 \times 23.30)$.

Conclusions This demonstrates a potential promising role of IF as adjuvant therapy on the evolution of symptomatology to COVID-19 patients.

\section{Introduction}

The coronavirus disease (COVID-19), caused by the severe acute respiratory syndrome coronavirus 2 (SARS-CoV-2), has being spread worldwide for more than 1 year. Although a vast knowledge has been gathered throughout this period, there are still limited, non-optimal treatment options. In this context, agents that can act on prophylaxis or as adjuvants to the therapies are of high value.

When it comes to the pathological mechanisms of the SARS-CoV-2, it is now clear the major involvement of the immune system with consequent (hyper)inflammatory effects. In fact, some authors consider that the disease presents itself in three stages: (I) Mild (early infection, viremia phase), (II) Moderate (Pulmonary Involvement with and without Hypoxia; pneumonia phase, inflammation in the lung), and (III) Severe (Systemic Hyperinflammation) or Recovery phase. ${ }^{1}$

In general, the three main findings common to all phases are lymphopenia (T-cell and, more specifically, $\mathrm{CD} 8^{+} \mathrm{T}$ cells), imbalance between Th1 and Th2 responses (leading to cytokine storm and inflammasome activation), and decreased circulating eosinophil numbers. ${ }^{2}$

$\mathrm{CD}^{+}$lymphopenia (with raised C-reactive protein, D-dimer and ferritin) has been linked to the severe progression of the disease, ${ }^{3,4}$ and it is shown to be reversible after patient recovery, notably for mild cases $^{5}$. When we consider previously known coronaviruses such as SARS-CoV- 1 and MERS-CoV, it is also understood that $\mathrm{T}$ cell immunity can play a decisive role in recovery and long-term protection of patients. ${ }^{6}$ 
In addition, it seems that T cell-mediated immune response is paramount for a good prognosis, as antibody responses in coronaviruses (SARS-CoV-1) are short-lived and can even aggravate lung pathology. ${ }^{6-8}$ This reduction in T cells subsets are also reported to be followed by an exhaustion of effector $\mathrm{T}$ cells, which contributes to the defective immune response against the virus. ${ }^{9,10}$

The dysfunctional immune response related to the reduced functional diversity of $\mathrm{T}$ cells in peripheral blood is also a key parameter to predict severity, as ICU/Stage III patients tend to show a more marked Th2 profile. ${ }^{3,11}$ This triggers a cytokine storm which, in turn, leads to inflammatory cell infiltration and consequent secretion of proteases and reactive oxygen species (oxidative stress), which altogether contribute to the lung damage and COVID-19 severity. ${ }^{12-14}$ This raise in inflammatory cytokines can be observed in peripheral blood ${ }^{15}$, as well as a reduced level of IFN- ${ }^{3}$, which is currently linked to a faster resolution of the infection. ${ }^{16}$

This knowledge brings up the concept of three points of action for improvement of symptomatology and faster recovery: regulation of the immune system, decrease of hyperinflammation and decrease of oxidative stress. Some treatments target on those have been already described and tested, but we focus here on a blend of ingredients that were first described by Ferreira et al. ${ }^{17}$ and with positive responses in isolated patients. ${ }^{18}$ This blend (further referred to as ImunoFormulation, IF) can potentially play a role in the prevention and/or support treatment of the symptomatology associated with COVID-19. The IF consist of: transfer factors (oligo- and polypeptides from porcine spleen, ultrafiltered at < $10 \mathrm{kDa}-$ Imuno $\mathrm{TF}^{\circledR}$ ) $100 \mathrm{mg}, 800 \mathrm{mg}$ anti-inflammatory natural blend (Uncaria tomentosa, Endopleura uchi and Haematoccocus pluvialis - Miodesin ${ }^{\mathrm{TM}}$ ), $60 \mathrm{mg}$ zinc orotate, $48 \mathrm{mg}$ selenium yeast (equivalent to $96 \mu \mathrm{g}$ of $\mathrm{Se}), 20,000 \mathrm{IU}$ cholecalciferol, $300 \mathrm{mg}$ ascorbic acid, $480 \mathrm{mg}$ ferulic acid, $90 \mathrm{mg}$ resveratrol, $800 \mathrm{mg}$ spirulina, $560 \mathrm{mg} \mathrm{N}$-acetylcysteine, $610 \mathrm{mg}$ glucosamine sulphate potassium chloride, and $400 \mathrm{mg}$ maltodextrin-stabilized orthosilicic acid (equivalent to $6 \mathrm{mg}$ of $\mathrm{Si}$ - SiliciuMax ${ }^{\circledR}$ ). The quantities correspond to the daily intake of the IF, which can be split into 3 doses, taken every 8 hours.

Thus, given the lack of gold-standard treatments, the knowledge on the virus mechanisms, and the theoretical potential benefit of the above referred adjuvant therapy, we have clinically evaluated the added value of IF for mild cases of COVID-19. In this preliminary report, we describe the course of SARS-CoV-2 disease in the patients that did or did not receive IF, based on the duration of clinical symptoms, as the basis for future clinical trials.

\section{Methods}

\section{Study design}

This is a multicentre, retrospective, observational study to describe the course of SARS-CoV-2 disease in patients treated with IF. In parallel, a group of patients that did not receive IF during the course of the SARS-CoV-2 disease was used for comparison. All patients attended either one of two private clinics (Clinic Bascoy and Clínica Arvila Magna, Barcelona, Spain) from March to May 2020. Data were collected 
from medical registers from 02 July 2020 to 29 September 2020. All patients/participants provided written informed consent. All steps of the study were conducted in accordance with the Good Clinical Practice Guideline as defined by the International Conference on Harmonisation, the Declaration of Helsinki, and all applicable federal and local regulations and institutional review board guidelines. Ethical approval for was granted by the Medicinal Product Research Ethics Committee of Hospital de Mar, once the private clinics where the study was conduct do not possess their own Ethics Committee, and once this is a reference centre for clinical studies in the region.

Secondary objectives were: (i) to describe the profile of patients (age, sex, comorbidities, concomitant medications and potential risk factors for contagion); (ii) to describe the course of SARS-CoV-2 disease in patients treated or not with IF based on the presence of symptoms at the time of the visit, two weeks and one month after the first visit for symptoms of the disease; (iii) to describe the course of SARS-CoV-2 disease in patients treated or not with IF based on the severity of the symptoms at the time of the visit, two weeks and one month after the first visit for symptoms of the disease; and (iv) to describe the adverse reactions (serious and non-serious) recorded in the patients' medical records during treatment with IF.

\section{Study population}

It was planned to collect data from approximately 40 patients who had tested positive in a diagnostic test for SARS-CoV-2: 20 patients who have had treated with IF and these results were compared with 20 patients who had received standard care only. Both cohorts were included without restrictions on the adjuvant treatment received.

All patients who met the screening criteria and gave their informed consent to participate were included consecutively. Inclusion criteria: patients aged 18 years or older; patients who give written informed consent to participate in the study; patients who have consulted their physician for symptoms associated with SARS-CoV-2 infection between March 2020 and May 2020; patients who have tested positive in a diagnostic test for SARS-CoV-2; patients with onset of COVID-19 symptoms $\geq 5$ days prior to diagnosis of SARS-CoV-2; patients with data in the medical record from the first visit due to disease symptoms until recovery, or at least 1 month of follow-up of symptoms, whichever occurs first. Exclusion criteria included: any medical or psychological condition that, in the physician's opinion, could compromise the patient's ability to give informed consent; patients requiring hospital admission due to the disease.

Sample size calculation was established according to the $\mathrm{ICH}$ guidelines, where it was specified that the number of patients should be sufficient to provide a safe response about the issues raised. According to Lechien et al. (2020) ${ }^{19}$, the mean duration of mild/moderate symptoms of COVID-19 was $11.5 \pm 5.7$ days. A sample of 18 patients would be sufficient to estimate, with a $95 \%$ confidence and a precision of \pm 2.8 days, a mean duration of symptoms with a standard deviation of 5.7 days. Assuming a loss of $10 \%$ of 
patients, the sample size was 20 patients. The calculations were performed with the help of the PASS package, version 2011.

\section{Data processing and debugging}

Study data were collected in a CRD and inserted the data in a database specifically designed for the study. The database included internal consistency ranges and rules to ensure data quality control. Data recorded during the study were checked. If incomplete responses or abnormal values were seen, a query was issued to the investigator to resolve the discrepancy. When all data have been recorded and all discrepancies resolved, the database was locked the analysis was performed by the statistics department.

\section{Data analysis and statistical tests}

The analyses of the primary and secondary objectives were performed from a single evaluable patient sample, including all patients meeting the inclusion criteria and none of the exclusion criteria. This sample of evaluable patients (EVAL set) for the description of the course of the disease was also be used for the description of the sample and the variables. Safety analyses of the secondary objective were performed on patients who have signed the informed consent (SAF set).

For comparisons between periods of continuous variables, parametric (Student's $t$ test for paired data) and non-parametric (Wilcoxon) tests were used, as appropriate, according to the characteristics of the study variables (assumption of normality), while categorical variables were compared using the McNemar test. The statistical tests used for comparison of the variables depended on the nature of the latter and based on the characteristics of the study variables and the number of groups to compare. The comparison between groups of quantitative variables were made using parametric (Student's $t$ or ANOVA) or non-parametric tests (Mann-Whitney or Kruskal-Wallis); comparison between groups of qualitative variables were made using chi-square test or Fisher test. Statistical significance level of 0.05 was used for all statistical tests. All calculations were performed using the SAS statistical software package, version 9.4.

\section{Results}

A total of 40 patients were recruited (20 in the ImmunoFormulation cohort / 20 in the Control cohort). Finally, 39 patients were Evaluable (EVAL set) (20 ImmunoFormulation cohort / 19 Control cohort) for efficacy variables (Figure 1). The control cohort received standard care only, while the ImmunoFormulation cohort received standard care and the IF, prepared by a local compounding pharmacy (concomitant medication during the observational study is summarized in Table S1). The median time between the first consultation for symptomatology and positive diagnosis test for SARS- 
CoV-2 was 6.00 days in the IF and 15.00 days in the Control cohort, observing statistically significant differences $(p=0.0004)$ (Table 1 , which also describes the population's sociodemographic data and the profile of comorbidities).

Table 1. Patient's characteristics upon the first consultation for symptomatology associated with SARSCoV-2 infection. 
Age, year [mean (SD) ${ }^{*}$

$54.25(14.24)$

Male gender, $\mathrm{n}(\%)$

$9(45.0)$

Time between first consultation for symptomatology and positive diagnosis for SARS-CoV-2, days [median $(25 ; \mathrm{P} 75)]^{\star}$

Time between the start date of the first symptom and start date of the ImmunoFormulation treatment, days [median (25; P75)]

\section{Type of patient according to the most common severity first symptom ${ }^{\mathrm{a}}$}

Predominance of mild severity, $\mathrm{n}(\%)$

$10(50.0)$

Predominance of moderate severity, $\mathrm{n}(\%)$

$6(30.0)$

Predominance of severe severity, $\mathrm{n}(\%)$

$4(20.0)$

\section{Comorbidities ${ }^{*}(\mathrm{n}=8$ patients with 14 relevant comorbidities)}

Cardiac disorders, $\mathrm{n}(\%)$

Vascular disorders, $\mathrm{n}(\%)$

Endocrine disorders, $\mathrm{n}(\%)$

Musculoskeletal disorders, $\mathrm{n}(\%)$

Neoplasms, $\mathrm{n}(\%)$

Nervous system disorders, $\mathrm{n}(\%)$

Psychiatric disorders, $\mathrm{n}(\%)$

Renal disorders, $\mathrm{n}(\%)$

Respiratory disorders, $\mathrm{n}(\%)$

\section{Characteristics Control}

Age, year [mean (SD)] *

Male gender, $\mathrm{n}(\%)$

Time between first consultation for symptomatology and positive diagnosis for SARS-CoV-2, days [median (25; P75)] *

Time between the start date of the first symptom and start date of the ImmunoFormulation treatment, days [median (25; P75)]
$0(0.0)$

$4(28.6)$

$1(7.1)$

$1(7.1)$

$3(21.4)$

$0(0.0)$

$0(0.0)$

$0(0.0)$

$2(14.3)$

Control cohort

(n=19)

81.16 (11.30)

3 (15.8)

$15.00(6.00 ; 21.00)$

Type of patient according to the most common severity first symptom ${ }^{a}$ 
Predominance of mild severity, $\mathrm{n}(\%)$

Predominance of moderate severity, $\mathrm{n}(\%)$

Predominance of severe severity, $\mathrm{n}(\%)$
$7(36.8)$

$5(26.3)$

$7(36.3)$

\section{Comorbidities $^{* *}$ ( $n=19$ patients with 52 relevant comorbidities)}

Cardiac disorders, n (\%)

Vascular disorders, $\mathrm{n}(\%)$

Endocrine disorders, $\mathrm{n}$ (\%)

Musculoskeletal disorders, n (\%)

Neoplasms, $\mathrm{n}(\%)$

Nervous system disorders, $\mathrm{n}(\%)$

Psychiatric disorders, $\mathrm{n}(\%)$

Renal disorders, $\mathrm{n}(\%)$

Respiratory disorders, $\mathrm{n}(\%)$
$11(21.2)$

$14(26.9)$

$0(0.0)$

$4(7.7)$

$0(0.0)$

$1(1.9)$

$5(9.6)$

$2(3.8)$

$4(7.7)$

${ }^{a}$ A single patient could have more than one symptom. In this case, the most common first symptomwas analysed. When groups would be directly compared, characteristics indicated by asterisk are statistically different $(p<0.05)$.

Overall, most common first symptoms were (Table S2): weakness (53.8\%), fever (51.3\%), dry cough (41.0\%), dyspnoea (30.8\%) and headache (17.9\%). In the ImmunoFormulation cohort the most common first symptoms were: weakness $(60.0 \%)$, headache $(30.0 \%)$, abdominal pain $(20.0 \%)$ and general discomfort (20.0\%). In the Control cohort the most common first symptoms were: fever (89.5\%), dry cough (68.4\%), dyspnoea (57.9\%), weakness (47.4\%) and hypoxemia (21.1\%). Statistically significant differences between cohorts were observed in fever $(p<0.0001)$, dry cough $(p=0.0011)$, dyspnoea $(p=0.0004)$ and hypoxemia $(p=0.0471)$. Patients were classified for the severity of their first severity symptoms according to the most common first symptoms: In the ImmunoFormulation cohort the $50.0 \%$ of the patients were classified as mild, $30.0 \%$ as moderate and $20.0 \%$ as severe (Table 1 ). In the Control cohort $36.8 \%$ of the patients were classified as mild, $26.3 \%$ as moderate and $36.8 \%$ as severe. No statistically significant differences between cohorts were observed $(p=0.4927)$. Detailed information on each symptom can be found in Table S3.

\section{Primary outcomes}


Throughout the observational period, $90 \%$ of patients recovered in the ImmunoFormulation cohort and $47.4 \%$ in the Control cohort ( $p=0.0057$ ) (Figure 2). According to the most severe first symptoms, in the ImmunoFormulation cohort, the mean (SD) days with some symptoms from the start of IF treatment to the end of the observational period was 11.22 (10.06) days in mild symptoms, 17.57 (8.36) days in moderate symptoms and 16.00 (8.76) days in severe symptoms. In the Control cohort, the mean (SD) days with some symptoms to the end of the observational period (end observational period - start first symptom) was 28.00 (4.47) days in mild symptoms, 28.00 (4.47) days in moderate symptoms and 25.42 (5.52) days in severe symptoms (Table S4).

The duration of symptoms in both cohorts (time to recover from start of the first symptom), as well as the percentage of recovery of each symptom by the end of the observational period is described in Table 2 . From the symptoms with statistically significant differences, the duration of symptoms (i.e., the time to recover from it) was shorter in the ImmunoFormulation cohort, especially for fever, headache, and weakness, which ended in less than 2 days. As for the adverse reactions' evaluation, no patient presented adverse drug reactions (Table 3).

Table 2. Total recovery duration of symptoms associated with COVID-19 stratified by the most common symptoms. 


\begin{tabular}{|c|c|c|c|}
\hline \multirow[t]{2}{*}{ Symptom } & \multicolumn{2}{|l|}{ ImmunoFormulation cohort } & \multirow{2}{*}{$\begin{array}{l}\text { Control cohort } \\
\text { Time to recover from start of the } \\
\text { first symptom / patients recovered } \\
\text { by the end of the observational } \\
\text { period }\end{array}$} \\
\hline & $\begin{array}{l}\text { Time to recover from start of the } \\
\text { first symptom / patients recovered } \\
\text { by the end of the observational } \\
\text { period }\end{array}$ & $\begin{array}{l}\text { Time to } \\
\text { recover } \\
\text { from start } \\
\text { of } \\
\text { treatment }\end{array}$ & \\
\hline Fever $^{*}$ & $3.35(2.87) / 100.0 \%$ & $\begin{array}{l}2.25(0.91) \\
/ 100.0 \%\end{array}$ & $21.78(7.75) / 66.7 \%$ \\
\hline Dry cough ${ }^{*}$ & $6.15(6.52) / 100.0 \%$ & $\begin{array}{l}4.38(6.31) \\
/ 100.0 \%\end{array}$ & $24.00(7.39) / 53.3 \%$ \\
\hline Dyspnoea* & $5.67(6.35) / 100.0 \%$ & $\begin{array}{l}3.67(2.08) \\
/ 100.0 \%\end{array}$ & $20.00(7.29) / 71.4 \%$ \\
\hline \multirow{2}{*}{$\begin{array}{l}\text { Loss of } \\
\text { taste and } \\
\text { smell }\end{array}$} & \multirow[t]{2}{*}{$21.55(7.27) / 90.9 \%$} & \multirow{2}{*}{$\begin{array}{l}19.73 \\
(4.67) / \\
90.9 \%\end{array}$} & $26.50(4.95) /$ \\
\hline & & & $0.0 \%$ \\
\hline Headache $^{*}$ & $6.25(1.98) / 100.0 \%$ & $\begin{array}{l}2.00(1.31) \\
/ 100.0 \%\end{array}$ & $26.50(4.95) / 0.0 \%$ \\
\hline Diarrhoea* & $8.75(4.35) / 100.0 \%$ & $\begin{array}{l}5.25(5.85) \\
/ 100.0 \%\end{array}$ & $25.25(3.20) / 25.0 \%$ \\
\hline Weakness* & $7.42(1.08) / 100.0 \%$ & $\begin{array}{l}1.92(0.67) \\
/ 100.0 \%\end{array}$ & $23.30(9.37) / 50.0 \%$ \\
\hline
\end{tabular}

${ }^{*} \mathrm{p}<0.05$ (ImmunoFormulation $x$ Control cohorts, in relation to time to recover from start of first symptom). Only symptoms present in more than 2 patients in each group are shown (full overview is shown in Tables S5 and S6).

Table 3. Adverse drug reactions in the ImmunoFormulation cohort.

\begin{tabular}{|ll|}
\hline Patients with adverse drug reactions & ImmunoFormulation cohort, $\mathrm{n}(\%)$ \\
\hline Adverse reactions patients (ADR) & $20(100.0 \%)$ \\
\hline Patients with adverse drug reactions & $0(0.0 \%)$ \\
\hline Patients without adverse drug reactions & $20(100.0 \%)$ \\
\hline
\end{tabular}

\section{Discussion}

The lack of standard treatment for COVID-19 creates the need for investigation of strategies that can either target SARS-CoV-2 to eliminate it or to improve the symptomatology and strengthen the natural defences. We aimed on this second option and evaluated the use of an add-on therapy described 
previously on literature. ${ }^{17,18}$ Comparing the two cohorts, a clear difference was seen in the resolution of most symptoms, including fever, dry cough, dyspnoea, headache, diarrhoea, and weakness. Overall, the reduction in time for the resolution of the symptoms indicate a possible positive effect for IF as an addon therapy for COVID-19.

Robust studies showing the time for recovery of symptoms are still lacking, as most of them focus on the time for symptom onset and in the rate of recovery/complications. The time from exposure to symptom onset is usually reported as is in average 11.5 days, and the time between symptom onset and hospital admission about 7 days. ${ }^{20,21}$ Usually the first symptoms (Stage I: fever, dry cough, headache, diarrhoea) appear between 0 to 4 days; the Stage II symptoms (hypoxia) in 5-13 days; and Stage III symptoms (ARDS, cardiac failure, shock) after 14 days of infection. ${ }^{1}$ This is in concordance with what was found by Wang et al, a median 5 days (range 2-8 days) for the progression from mild-moderate cases to severe condition, and a hospital stay range from 14 to 22 days. $^{22}$

As an attempt for comparison, Carfi et al..$^{23}$ evaluated a population similar to our IF cohort in sociodemographic terms: patients with mean age of $56.5( \pm 14.6)$ years, and $63 \%$ were men; the difference is that they evaluated hospitalized patients. They assessed the patients for a mean of 60.3 days after onset of the first COVID-19 symptom and observed that only $12.6 \%$ were completely free of any COVID-19-related symptom, while $32 \%$ had 1 or 2 symptoms and $55 \%$ had 3 or more. A report from Imperial College of London ${ }^{24}$ showed that the mean time for recovery after symptom onset is 20.51 ( \pm 6.69) days. In contrast, $90.0 \%$ of the IF cohort of the present study recovered during the observational period (30 days), and the most common symptoms were resolved within around 2 to five days (except for loss of taste and smell, which is known to be a long-lasting or irreversible complication of COVID-1925).

A similar population studied was also reported by Chen et al. ${ }^{26}$ : patients with mild cases, a median of 51 years, and a percentage of $50.6 \%$ men. In this study, the estimated median duration of fever was 10 days (Cl: 8-11 days), after onset of symptoms - in our findings, the duration of fever was 3.35 days after the onset of symptoms and 2.25 days after the start of treatment.

Obtaining fast patient recovery is important, as the persistence of symptoms can reflect the worsening in his prognosis. For example, for severe cases, the symptoms can last for more than 28 days, leading to hyperinflammation/hypercoagulation responses and pulmonary fibrosis formation. ${ }^{27}$

The improvement in the time needed for recovery of the symptoms in the IF cohort can be related to the multiple mechanisms that the components of the IF theoretically acts on as described earlier by Ferreira et al. ${ }^{17}$ We will highlight four. First, immune system regulation. This can be related to macrophage activation by Imuno $\mathrm{TF}^{\circledR 28,29}$ and spirulina, ${ }^{30,31}$ to development of neutrophils by Spirulina and Zinc, ${ }^{32}$ to activation of NK-cells by Imuno TF ${ }^{\circledR}$, Spirulina, Zinc, Vitamin C, and Resveratrol, ${ }^{31,33-38}$ to the increase in T-cells functions by Spirulina, Vitamin $\mathrm{C}$ and Vitamin $\mathrm{D}_{3},{ }^{32,39-41}$ and to $\mathrm{CD} 4^{+}$cells activation by Imuno $\mathrm{TF}^{\circledR}$ and Selenium, which can regulate the antigenic stimulus triggering $\mathrm{CD} 4^{+}$Th 1 cells to produce IFN- $\gamma$, 
IL-1 and TNF- $\alpha .{ }^{28,29,32,42-44}$ In addition, Imuno TF ${ }^{\circledR}$ positively regulates Th1 cytokines, while decreases the release of Th2 cytokines (IL-4, IL-5, IL-6, IL-13) ${ }^{45}$ This is relevant once there is evidence that the Th2 overresponse are linked to bronchoconstriction, dyspnea and exacerbations of allergic airways diseases. $^{46}$

Secondly, targeting the virus itself: Resveratrol have demonstrated DPP4R inhibitory effect (also observed with the use of N-acetylcysteine) and potential to block the ACE2' binding site; 47,48 and Zinc (high concentration, intracellular) can inhibit the RNA polymerase. ${ }^{49}$ In addition, $\mathrm{N}$-acetylcysteine, Selenium, and Glucosamine can amplify the signalling functions of TLR7. ${ }^{50}$ Recently, U. tomentosa bark extract (one of the components of Miodesin ${ }^{\mathrm{TM}}$ ) has shown antiviral effect against SARS-CoV-2 on Vero E6 cells. ${ }^{51}$

Third, the IF effects on the inflammatory process generated by the infection. Vitamin $D_{3}$ possesses antiinflammatory properties and can decrease the cytokines storm, ${ }^{52-58}$ notably decreasing the IL-6 effect, a marker of severity in COVID-19 patients. ${ }^{45,59}$ Vitamin C is related to an increase in lymphocytes $B$ and T proliferation and differentiation. ${ }^{40,65,66}$ Resveratrol and Ferulic acid were reported to inhibit the TLR4 signalling pathway ${ }^{50}$ - Ferulic acid can also diminish the serological concentration of TNF-a and IL$1 \beta .{ }^{67,68}$ Another ingredient, Miodesin ${ }^{\mathrm{TM}}$, was shown recently to decrease inflammation through inhibition of the release of cytokines (IL-1 $\beta$, IL-6, IL-8, and TNF- $a$ ) and chemokines (CCL2, CCL3, and CCL5) and the expression of NF-KB, inflammatory enzymes (COX-1, COX-2, PLA2, iNOS), and chemokines (CCL2, CCL3, and CCL5). ${ }^{69}$

Finally, the add-on treatment provided was idealized to also act on the oxidative stress. Phase 2 inductive nutraceuticals as Ferulic acid and Resveratrol induce various peroxidase enzymes and promote synthesis of glutathione. Glutathione production can also be promoted by administration of N-acetylcysteine. Selenium supplementation might also be appropriate in this context. ${ }^{50}$ Besides, other nutraceuticals with antioxidant properties such as Vitamin C, Spirulina and Astaxanthin can also contribute to reduce the oxidative stress. . $^{50,65,66,70-73}$

As a limitation of our study, we can point out the differences in age of the cohorts. Therefore, we can understand the data as a description of the fast times needed to recover from the most common COVID19 symptoms, rather than a direct comparison between the cohorts.

\section{Conclusion}

This retrospective observational study demonstrates a potential promising role of ImmunoFormulation as adjuvant therapy on the evolution of symptomatology to COVID-19 patients. Specially for the symptoms fever, dry cough, dyspnoea, headache, diarrhoea and weakness, the recovery time for the treated cohort was significant shorter in comparison to the control cohort. A controlled, double-blind, randomized clinical trial in a larger population is therefore currently being conducted. 


\section{Declarations}

\section{Ethics approval and consent to participate}

All patients/participants provided written informed consent. All steps of the study were conducted in accordance with the Good Clinical Practice Guideline as defined by the International Conference on Harmonisation, the Declaration of Helsinki, and all applicable federal and local regulations and institutional review board guidelines. Ethical approval for was granted by the Medicinal Product Research Ethics Committee of Hospital de Mar, once the private clinics where the study was conduct do not possess their own Ethics Committee, and once this is a reference centre for clinical studies in the region.

\section{Consent for publication}

Not applicable

\section{Availability of data and materials}

The datasets during and/or analysed during the current study are available from the corresponding author on reasonable request.

\section{Competing interests}

The authors work as consultants for Fagron Iberica S.A.U.

\section{Funding}

This study was conducted under the sponsorship of Fagron BV.

\section{Authors' contributions}

$\mathrm{MDH}, \mathrm{JU}$ and LB provided the design of the study and collection of data. MDH and JU wrote and revised the manuscript. All authors read and approved the final manuscript.

\section{References}


1. Siddiqi HK, Mehra MR. COVID-19 Illness in Native and Immunosuppressed States: A ClinicalTherapeutic Staging Proposal. J Hear Lung Transplant. Published online 2020.

2. Azkur AK, Akdis M, Azkur D, et al. Immune response to SARS-CoV-2 and mechanisms of immunopathological changes in COVID-19. Allergy Eur J Allergy Clin Immunol. 2020;75(7):15641581. doi:10.1111/all.14364

3. Oja AE, Saris A, Ghandour CA, et al. Divergent SARS-CoV-2-specific T and B cell responses in severe but not mild COVID-19 patients. Eur J Immunol. Published online 2020:1-15. doi:10.1002/eji.202048908

4. Liao M, Liu Y, Yuan J, et al. Single-cell landscape of bronchoalveolar immune cells in patients with COVID-19. Nat Med. 2020;26(6):842-844. doi:10.1038/s41591-020-0901-9

5. Altmann DM, Boyton RJ. SARS-CoV-2 T cell immunity: Specificity, function, durability, and role in protection. Sci Immunol. 2020;5(49):2-7. doi:10.1126/sciimmunol.abd6160

6. Nelde A, Bilich T, Heitmann JS, et al. SARS-CoV-2-derived peptides define heterologous and COVID19-induced T cell recognition. Nat Immunol. Published online 2020. doi:10.1038/s41590-020-00808$\mathrm{X}$

7. Liu L, Wei Q, Lin Q, et al. Anti-spike IgG causes severe acute lung injury by skewing macrophage responses during acute SARS-CoV infection. JCl ilsight. 2019;4(4):e123158. doi:10.5603/fm.a2020.0011

8. Tang F, Quan Y, Xin Z-T, et al. Lack of Peripheral Memory B Cell Responses in Recovered Patients with Severe Acute Respiratory Syndrome: A Six-Year Follow-Up Study. J Immunol. 2011;186(12):72647268. doi:10.4049/jimmunol.0903490

9. Diao B, Wang C, Tan Y, et al. Reduction and Functional Exhaustion of T Cells in Patients With Coronavirus Disease 2019 (COVID-19). Front Immunol. 2020;11:827.

10. Zheng HY, Zhang M, Yang CX, et al. Elevated exhaustion levels and reduced functional diversity of $T$ cells in peripheral blood may predict severe progression in COVID-19 patients. Cell Mol Immunol. 2020;17(5):541-543. doi:10.1038/s41423-020-0401-3

11. Qin C, Zhou L, Hu Z, et al. Dysregulation of Immune Response in Patients With COVID-19 in Wuhan, China. Clin Infect Dis. Published online 2020.

12. Tay MZ, Poh CM, Rénia L, MacAry PA, Ng LFP. The trinity of COVID-19: immunity, inflammation and intervention. Nat Rev Immunol. 2020;20(6):363-374. doi:10.1038/s41577-020-0311-8

13. Blanco-Melo D, Nilsson-Payant BE, Liu WC, et al. Imbalanced Host Response to SARS-CoV-2 Drives Development of COVID-19. Cell. 2020;181(5):1036-1045.e9. doi:10.1016/j.cell.2020.04.026

14. Shah VK, Firmal P, Alam A, Ganguly D, Chattopadhyay S. Overview of Immune Response During SARS-CoV-2 Infection: Lessons From the Past. Front Immunol. 2020;11 (August):1-17. doi:10.3389/fimmu.2020.01949

15. Nasab MG, Saghazadeh A, Rezaei N. SARS-CoV-2-A Tough Opponent for the Immune System. Arch Med Res. 2020;51(6):589-592. doi:10.1016/j.arcmed.2020.05.020 
16. Pierce CA, Preston-Hurlburt P, Dai Y, et al. Immune responses to SARS-CoV-2 infection in hospitalized pediatric and adult patients. Sci Trans/ Med. 2020;12(564). doi:10.1126/scitransImed.abd5487

17. Ferreira AO, Polonini HC, Djikers ECF. Postulated add-on therapeutic strategies for COVID-19. Nutrients. 2020;10(3):80.

18. Díaz M, Bascoy L. Immunoformulation for COVID-19. Encycl. Published online 2020.

19. Lechien JR, Chiesa-Estomba CM, Place S, et al. Clinical and epidemiological characteristics of 1420 European patients with mild-to-moderate coronavirus disease 2019. J Intern Med. 2020;288(3):335344. doi:10.1111/joim. 13089

20. Faes C, Abrams S, Van Beckhoven D, Meyfroidt G, Vlieghe E, Hens N. Time between symptom onset, hospitalisation and recovery or death: Statistical analysis of belgian covid-19 patients. Int J Environ Res Public Health. 2020;17(20):1-18. doi:10.3390/ijerph17207560

21. Wiersinga WJ, Rhodes A, Cheng AC, Peacock SJ, Prescott HC. Pathophysiology, Transmission, Diagnosis, and Treatment of Coronavirus Disease 2019 (COVID-19): A Review. JAMA - J Am Med Assoc. 2020;324(8):782-793. doi:10.1001/jama.2020.12839

22. Wang $F$, Qu M, Zhou $X$, et al. The timeline and risk factors of clinical progression of COVID-19 in Shenzhen, China. J Trans/ Med. 2020;18(1):1-11. doi:10.1186/s12967-020-02423-8

23. Carfi A, Bernabei R, Landi F. Persistent Symptoms in Patients After Acute COVID-19. J Am Med Assoc. 2020;324(6):603-605. doi:10.1056/nejmp2014836

24. Gaythorpe K, Imai N, Cuomo-dannenburg G, et al. Symptom progression of COVID-19. Imp Coll London COVID-19 Response Team. 2020;(11 March):1-10.

25. Parma V, Ohla K, Veldhuizen MG, et al. More Than Smell-COVID-19 Is Associated With Severe Impairment of Smell, Taste, and Chemesthesis. Chem Senses. 2020;45(7):609-622. doi:10.1093/chemse/bjaa041

26. Chen J, Qi T, Liu L, et al. Clinical progression of patients with COVID-19 in Shanghai, China. J Infect. 2020;80(5):e1-e6. doi:10.1016/j.jinf.2020.03.004

27. Polak SB, Van Gool IC, Cohen D, von der Thüsen JH, van Paassen J. A systematic review of pathological findings in COVID-19: a pathophysiological timeline and possible mechanisms of disease progression. Mod Pathol. 2020;33(11):2128-2138. doi:10.1038/s41379-020-0603-3

28. Krishnaveni M. A review on transfer factor an immune modulator. Drug Invent Today. 2013;5(2):153156. doi:10.1016/j.dit.2013.04.002

29. Kirkpatrick CH. Biological Response Modifiers. Interferons, Interleukins, and Transfer Factor. Ann Allergy. 1989;62(3):170-176.

30. Khan Z, Bhadouria P, Bisen P. Nutritional and Therapeutic Potential of Spirulina. Curr Pharm Biotechnol. 2005;6(5):373-379. doi:10.2174/138920105774370607

31. Hirahashi T, Matsumoto M, Hazeki K, Saeki Y, Ui M, Seya T. Activation of the human innate immune system by Spirulina: Augmentation of interferon production and NK cytotoxicity by oral 
administration of hot water extract of Spirulina platensis. Int Immunopharmacol. 2002;2(4):423-434. doi:10.1016/S1567-5769(01)00166-7

32. Cicero AFG, Colletti A. Handbook of Nutraceuticals for Clinical Use.; 2018. doi:10.1007/978-3-319$73642-6$

33. Krinsky DL, Lavalle JB, Hawkins EB. Lexi-Comp's Natural Therapeutics Pocket Guide.; 2003.

34. Baum MK, Campa A, Lai S, Lai H, Page JB. Zinc Status in Human Immunodeficiency Virus Type 1 Infection and Illicit Drug Use. Clin Infect Dis. 2003;37(Suppl.2):S117-S123.

35. Hojyo S, Fukada T. Roles of Zinc Signaling in the Immune System. J Immunol Res. 2016;2016. doi:10.1155/2016/6762343

36. Heuser G, Vojdani A. Enhancement of natural killer cell activity and $T$ and B cell function by buffered vitamin $\mathrm{C}$ in patients exposed to toxic chemicals: The role of protein kinase - C. Immunopharmacol Immunotoxicol. 1997;19(3):291-312. doi:10.3109/08923979709046977

37. Li Q, Huyan T, Ye LJ, Li J, Shi JL, Huang QS. Concentration-dependent biphasic effects of resveratrol on human natural killer cells in vitro. J Agric Food Chem. 2014;62(45):10928-10935. doi:10.1021/jf502950u

38. Leischner C, Burkard M, Pfeiffer MM, Lauer UM, Busch C, Venturelli S. Nutritional immunology: Function of natural killer cells and their modulation by resveratrol for cancer prevention and treatment. Nutr J. 2016;15(1):1-12. doi:10.1186/s12937-016-0167-8

39. Park HJ, Lee YJ, Ryu HK, Kim MH, Chung HW, Kim WY. A randomized double-blind, placebo-controlled study to establish the effects of spirulina in elderly Koreans. Ann Nutr Metab. 2008;52(4):322-328. doi:10.1159/000151486

40. Carr AC, Maggini S. Vitamin C and immune function. Nutrients. 2017;9(11):1-25. doi:10.3390/nu9111211

41. Seaborn CD, Briske-Anderson M, Nielsen FH. An interaction between dietary silicon and arginine affects immune function indicated by con-a-induced dna synthesis of rat splenic T-lymphocytes. Biol Trace Elem Res. 2002;87(1-3):133-142. doi:10.1385/BTER:87:1-3:133

42. Hoffman PR, Berry MJ. The influence of selenium on immune responses. Mol Nutr Food Res. 2008;52(11):1273-1280.

43. Garritano CRO, Di Nubila F, Couto RM, Fiorelli RKA, Aun LB. Avaliação do uso de fator de transferência na resposta imunológica de pacientes cirúrgicos imunodeprimidos. Rev Col Bras Cir. 2017;44(5):452-456. doi:10.1590/0100-69912017005005

44. White A. Transfer Factors \& Immune System Health. 2nd ed. U.S.A.: BookSurge Publishing; 2009.

45. Rocha Oliveira C, Paula Vieira R, de Oliveira Ferreira A, Elisa de Souza Schmidt Gonçalves A, Polonini $\mathrm{H}$. Immunoregulatory effects of Imuno TF $®$ (transfer factors) on Th1/Th2/Th17/Treg cytokines. bioRxiv. Published online 2020:2020.11.06.371435. https://doi.org/10.1101/2020.11.06.371435

46. Roncati L, Nasillo V, Lusenti B, Riva G. Signals of Th2 immune response from COVID-19 patients requiring intensive care. Ann Hematol. 2020;99(6):1419-1420. doi:10.1007/s00277-020-04066-7 
47. Tang N, Bai H, Chen X, Gong J, Li D, Sun Z. Anticoagulant treatment is associated with decreased mortality in severe coronavirus disease 2019 patients with coagulopathy. J Thromb Haemost. 2020; (March):1094-1099. doi:10.1111/jth.14817

48. Laskar MA, Choudhury MD. Resveratrol a potent angiotensin converting enzyme inhibitor: A computational study in relevance to cardioprotective activity. Res J Pharm Biol Chem Sci. 2014;5(6):1109-1115.

49. te Velthuis AJW, van den WormI SHE, Sims AC, Baric RS, Snijder EJ, van Hemert MJ. Zn2+ inhibits coronavirus and arterivirus RNA polymerase activity in vitro and zinc ionophores block the replication of these viruses in cell culture. PLoS Pathog. 2010;6(11):1-10. doi:10.1371/journal.ppat.1001176

50. McCarty MF, DiNicolantonio JJ. Nutraceuticals Have Potential for Boosting the Type 1 Interferon Response to RNA Viruses Including Influenza and Coronavirus. Prog Cardiovasc Dis. Published online 2020:[Epub ahead of print].

51. Yepes-Perez AF, Herrera-Calderón O, Flórez-Álvarez L, et al. The hydroalcoholic extract of Uncaria tomentosa (Cat's claw) inhibits the replication of 2 novel coronavirus (SARS-CoV-2) in vitro. bioRxiv. Published online 2020.

52. Aranow C. Vitamin D and the immune system. J Investig Med. 2011;59(6):881-886. doi:10.3899/jrheum.090797

53. Grant WB, Lahore H, McDonnell SL, et al. Evidence that vitamin d supplementation could reduce risk of influenza and covid-19 infections and deaths. Nutrients. 2020;12(4):1-19. doi:10.3390/nu12040988

54. Hansdottir S, Monick MM. Vitamin D Effects on Lung Immunity and Respiratory Diseases. Vitam Horm. 2011;86(319):217-237. doi:10.1016/B978-0-12-386960-9.00009-5

55. Alipio M. Vitamin D Supplementation Could Possibly Improve Clinical Outcomes of Patients Infected with Coronavirus-2019 (COVID-2019). SSRN Electron J. 2020;2019(082):1-9. doi:10.2139/ssrn.3571484

56. Panarese A, Shahini E. Letter: Covid-19, and vitamin D. Aliment Pharmacol Ther. 2020;51(10):993995. doi:10.1111/apt.15752

57. Daneshkhah A, Eshein A, Subramanian H, Roy HK, Backman V. The Role of Vitamin D in Suppressing Cytokine Storm in COVID-19 Patients and Associated Mortality. medRxiv. 2020;25. doi:10.1101/2020.04.08.20058578

58. Molloy EJ, Murphy N. Vitamin D, Covid-19 and Children. Ir Med J. 2020;113(4):59.

59. McCartney DM, Byrne DG. Optimisation of Vitamin D Status for Enhanced Immuno-protection Against Covid-19. Ir Med J. 2020;113(4):58.

60. Lau FH, Majumder R, Torabi R, et al. Vitamin D Insufficiency is Prevalent in Severe COVID-19. medRxiv. 2020;(504):2020.04.24.20075838. doi:10.1101/2020.04.24.20075838

61. Carter SJ, Baranauskas MN, Fly AD. Considerations for obesity, vitamin D, and physical activity amidst the COVID-19 pandemic. Obesity. 2020;00(00):9-10. doi:10.1002/oby.22838 
62. Ilie PC, Stefanescu S, Smith L. The role of vitamin D in the prevention of coronavirus disease 2019 infection and mortality. Aging Clin Exp Res. 2020;(0123456789):8-11. doi:10.1007/s40520-02001570-8

63. Raharusun P, Priambada S, Budiarti C, Agung E, Budi C. Patterns of COVID-19 Mortality and Vitamin D: An Indonesian Study. SSRN Electron J. Published online 2020. doi:10.2139/ssrn.3585561

64. Rhodes JM, Subramanian S, Laird E, Anne Kenny R. Editorial: low population mortality from COVID19 in countries south of latitude 35 degrees North - supports vitamin D as a factor determining severity. Aliment Pharmacol Ther. Published online 2020:1434-1437. doi:10.1111/apt.15777

65. Anderson R, Oosthuizen R, Maritz R, Theron A, Van Rensburg AJ. The effects of increasing weekly doses of ascorbate on certain cellular and humoral immune functions in normal volunteers. $\mathrm{Am} \mathrm{J}$ Clin Nutr. 1980;33(1):71-76. doi:10.1093/ajcn/33.1.71

66. Anderson R. Ascorbate-mediated stimulation of neutrophil motility and lymphocyte transformation by inhibition of the peroxidase/H2O2/halide system in vitro and in vivo. Am J Clin Nutr. 1981;34(9):1906-1911. doi:10.1093/ajcn/34.9.1906

67. Yuan J, Ge K, Mu J, et al. Ferulic acid attenuated acetaminophen-induced hepatotoxicity though down-regulating the cytochrome P 2E1 and inhibiting toll-like receptor 4 signaling-mediated inflammation in mice. Am J Transl Res. 2016;8(10):4205-4214.

68. Zaffaroni L, Peri F. Recent advances on Toll-like receptor 4 modulation: New therapeutic perspectives. Future Med Chem. 2018;10(4):461-476. doi:10.4155/fmc-2017-0172

69. Oliveira CR, Vieira RP. Anti-Inflammatory Activity of Miodesin TM: Modulation of Inflammatory Markers and Epigenetic Evidence. Oxid Med Cell Longev. Published online 2020.

70. Gonçalves C, Dinis T, Batista MT. Antioxidant properties of proanthocyanidins of Uncaria tomentosa bark decoction: A mechanism for anti-inflammatory activity. Phytochemistry. 2005;66(1):89-98. doi:10.1016/j.phytochem.2004.10.025

71. Navarro M, Arnaez E, Moreira I, Hurtado A, Monge D, Monagas M. Polyphenolic composition and antioxidant activity of Uncaria tomentosa commercial bark products. Antioxidants. 2019;8(9). doi:10.3390/antiox8090339

72. Padayatty SJ, Katz A, Wang Y, et al. Vitamin C as an Antioxidant: Evaluation of Its Role in Disease Prevention. J Am Coll Nutr. 2003;22(1):18-35. doi:10.1080/07315724.2003.10719272

73. Yamashita E. Let astaxanthin be thy medicine. PharmaNutrition. 2015;3(4):115-122. doi:10.1016/j.phanu.2015.09.001

\section{Figures}




\section{Recruited patients}

$$
\mathrm{n}=40
$$
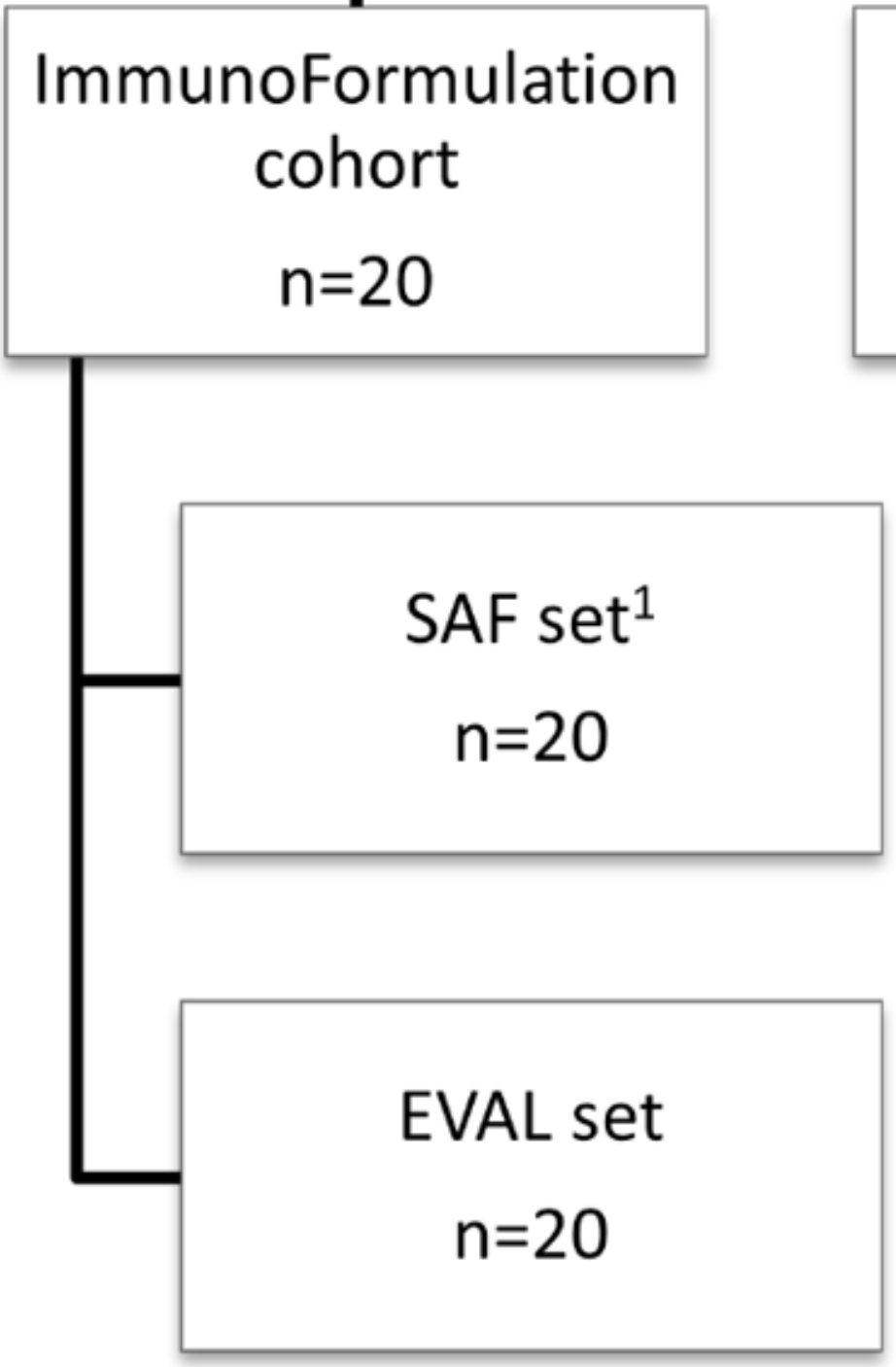

Control cohort$$
n=20
$$

\section{SAF set ${ }^{1}$}

$\mathrm{n}=--$

\section{EVAL set ${ }^{2}$ \\ $\mathrm{n}=19$}

Figure 1

Flow chart of the study. 1 Description of adverse reactions only were analysed in the ImmunoFormulation cohort. 2 One patient did not meet Inclusion Criterion (patients with onset of COVID-19 symptoms $\geq 5$ days prior to diagnosis of SARS-CoV-2). SAF = Safety. EVAL = Evaluable patients. 


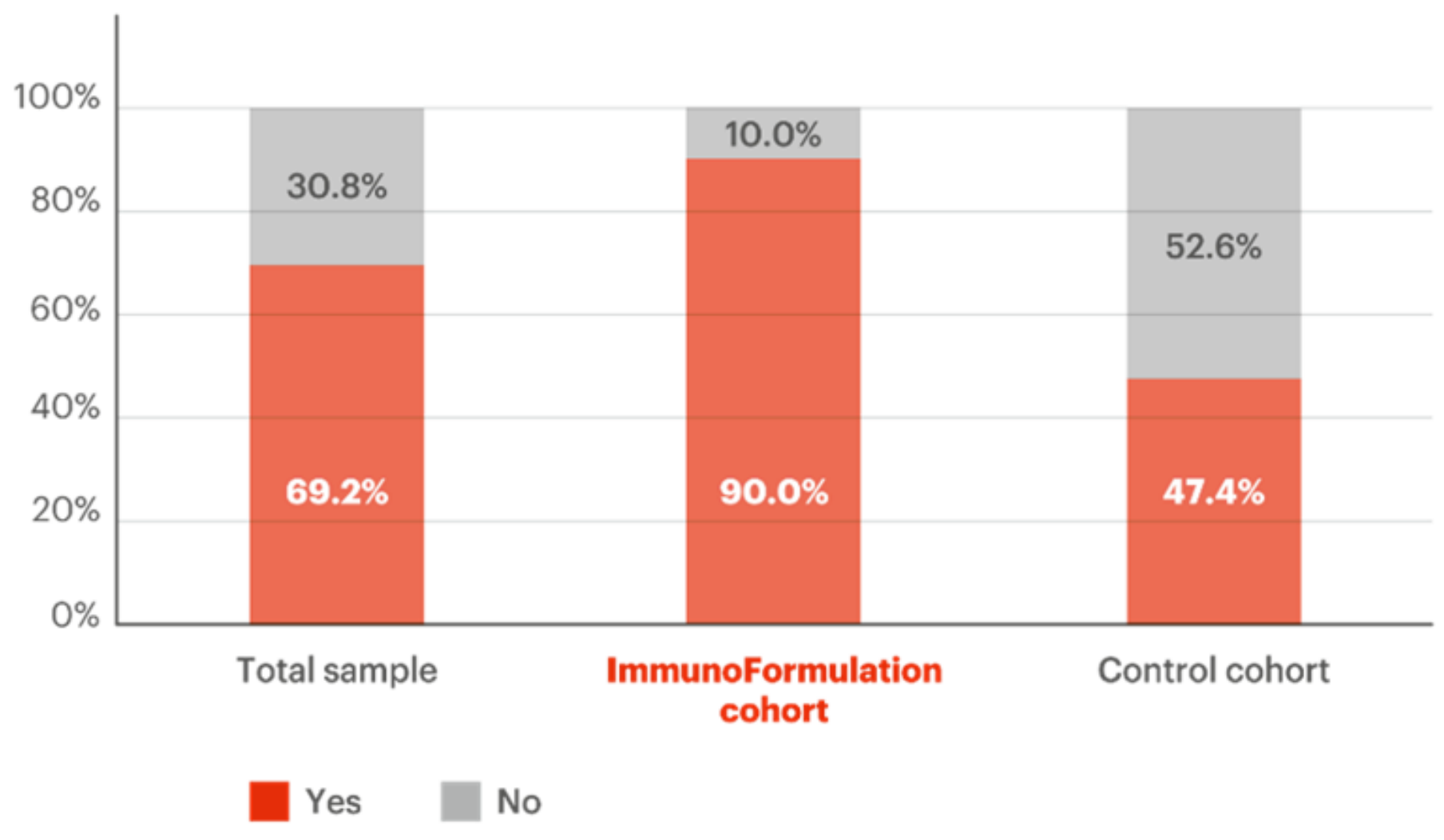

Figure 2

Patients recovered from start of the first symptom to the end of the observational period.

\section{Supplementary Files}

This is a list of supplementary files associated with this preprint. Click to download.

- BMCInfecDiselmmunoFormulationstudyfinalversionSupplementary.docx 